\title{
Towards empowering learners in a democratic mathematics classroom: To what extent are teachers' listening orientations conducive to and respectful of learners' thinking?
}

\author{
Authors: \\ Michael K. Mhlolo \\ Marc Schäfer ${ }^{1}$ \\ Affiliations: \\ ${ }^{1}$ Mathematics Education \\ Department, Rhodes \\ University, South Africa \\ Correspondence to: \\ Mike Mhlolo \\ Email: \\ m.mhlolo@ru.ac.za \\ Postal address: \\ PO Box 94, Grahamstown \\ 6140 , South Africa \\ Dates: \\ Received: 16 Mar. 2012 \\ Accepted: 06 Nov. 2012 \\ Published: 11 Dec. 2012 \\ How to cite this article: \\ Mhlolo, M.K., \& Schäfer, M. \\ (2012). Towards empowering \\ learners in a democratic \\ mathematics classroom: To \\ what extent are teachers' \\ listening orientations \\ conducive to and respectful \\ of learners' thinking? \\ Pythagoras, 33(2), Art. \#166, \\ 9 pages. http://dx.doi.org/ \\ 10.4102/pythagoras.v33i2.166
}

(C) 2012. The Authors. Licensee: AOSIS OpenJournals. This work is licensed under the Creative Commons Attribution License.
In an effort to make education accessible, to 'heal the divisions of the past and establish a society based on democratic values', the South African Department of Education claims that a series of mathematics reforms that has so far been introduced is underpinned by the principles of 'social justice, fundamental human rights and inclusivity'. Critics however argue that the system has remained 'undemocratic' in that those groups of learners who were supposed to be 'healed' continue to underperform and hence be disempowered. In this study, we conceptualised a democratic and mathematically empowering classroom as one that is consistent with the principle of inclusivity and in which a hermeneutic listening orientation towards teaching promotes such a democratic and mathematically empowering learning environment. We then worked with three different orientations teachers might have towards listening in the mathematics classroom: evaluative, interpretive and hermeneutic. We then used these orientations to analyse 20 video-recorded lessons with a specific focus on learners' unexpected contributions and how teachers listened and responded to such contributions. The results were consistent with the literature, which shows that teachers tend to dismiss learners' ways of thinking by imposing their own formalised constructions.

\section{Introduction}

In South Africa, despite many of the post-democracy education policies being acclaimed by curriculum experts, learners from previously disadvantaged schools continue to seriously underperform, prompting critics to argue that 'there is little evidence that goals of transformation, including redress, equity and democracy have been achieved in practice' (Sayed \& Jansen, 2001, p. 2; see also Fleisch, 2008; Muller, 2005; Volmink, 1994). Learner underperformance has been shown to be acute especially in mathematics, a subject generally viewed as a critical filter (gatekeeper) for economic access, higher education, full employment and participation within a democratic society (Stinson, 2004). In South Africa, implicit within these 'mathematics-as-agatekeeper' debates is the argument that learners from previously disadvantaged schools are not being provided with the 'key to the gate' (Stinson, 2004, p. 4) and are hence disempowered and excluded. In this article we argue that the concept of mathematics providing the key for passing through the gates to economic access, full citizenship and higher education is located at the core of learner-teacher relationships in the mathematics classroom. Our proposition is that probably the most important factor to be problematised is the quality of those learner-teacher relationships. From a mathematical empowerment perspective and with reference to the learnerteacher relationship, Volmink (1994) suggested that there is a kind of teacher guidance that has potential to be individually empowering whilst at the same time valuing the autonomy of the learner (democratic). The envisaged guidance must propel

those who have been marginalised, disinvited, and underrepresented ... to come to see that they too can share in the creation of mathematics and the transformation of their world. (p. 52)

Key to this guidance is the shift in power relations so that the teacher listens to pupils in depth and allows them to make and express judgements whilst at the same time valuing their contributions. This article problematises this learner-teacher relationship and the shift (or not) in power relations by analysing how teachers who participated in this study responded to learner contributions. In doing so we worked with classroom transcripts and raised the following questions to guide our analyses:

1. To what extent do mathematics teachers give learners authority with respect to their novel comments and actions?

2. What are the possible implications for democracy and empowerment of the learner? 


\section{Theoretical underpinnings}

Our concern in this article can be couched in the form of a question, borrowed from Stinson (2004):

If school mathematics is a gatekeeper, how might mathematics educators ensure that gate keeping mathematics becomes an inclusive instrument for empowerment rather than an exclusive instrument for stratification? (p. 9)

The concept of empowerment has been dealt with from diverse perspectives including political, social and economic, but in essence empowerment provides the subject with the skills and knowledge to make socio-political critiques about their surroundings and to take action (or not) against oppressive elements of those surroundings (Stinson, 2004).

\section{According to Ernest (2002):}

Empowerment is gaining of power in particular domains of activity by individuals or groups and the processes of giving power to them, or processes that foster and facilitate their taking power. (p. 1)

Ernest distinguished three different domains of empowerment concerning mathematics and its uses: mathematical, social and epistemological. None of these is either wholly discrete or unrelated in its modes of function. Mathematical empowerment concerns gaining power over the language, skills and practices of using mathematical knowledge. Social empowerment involves using mathematics as a tool for sociopolitical critique, gaining power over the social domains. Ernest viewed epistemological empowerment as summative and the culmination of both mathematical and social empowerment in that the empowered learner will not only be able to pose and solve mathematical questions (mathematical empowerment), but also be able to understand and begin to answer important questions relating to a broad range of social uses and abuses of mathematics (social empowerment). In this summative sense, epistemological empowerment concerns the individual's growth of confidence in not only using mathematics, but also a personal sense of power over the creation and validation of knowledge.

We found that this epistemological view of empowerment enabled us to move our argument forward in two important ways. Firstly, it allowed us to focus on the individual learners in a classroom situation. Ernest (2002) suggested that whilst different models have been developed to analyse the three perspectives of empowerment, the most neglected in discussions of aims of teaching and learning are those that have direct focus on developing epistemological powers of the individual. Yet Lather (1991), for example, emphasised that empowerment is a learning process one undertakes for oneself: 'it is not something done to or for someone' (p. 4). Epistemological empowerment addresses this issue in that it involves the development of learners' personal confidence, their sense of mathematical self-efficacy, as well as their sense of personal ownership of and power over mathematics. The emphasis is on self-empowerment and this is critical to our argument in this article as we question power relations, that is, whether or not the learner is explicitly or implicitly treated by authority (the teacher) as a passive receiver and user of knowledge.

Secondly, epistemological empowerment concerns personal power over the creation and validation of knowledge. It has to do with the teacher not only encouraging learners to make contributions to the classroom discourse but also acknowledging and supporting such learners' ways of understanding. It is this personal creation and validation of knowledge by the learners that we are putting under the spotlight in this article as we question the extent to which mathematics teachers acknowledge, support and build on learners' personal routes or ways of knowing. According to Boaler (2000):

If the students' social and cultural values are encouraged and supported in the mathematics classroom, through the use of contexts or through an acknowledgement of personal routes and direction, then their learning will have more meaning for them. (p. 17)

Within the multiplicity of perspectives on empowerment, different models have been suggested to analyse different scenarios. However, consistent with our concerns for selfempowerment of the learners, we felt compelled to turn to models of the development of the individual knower within a relationship of power, that is, the learner-teacher relationship. Ernest suggested a model developed by Belenky, Clinchy, Goldberger and Tarule (1986), which we found valuable because of its direct focus on developing epistemological powers of the individual. Whilst the Belenky et al. model had earlier been tried in other studies which did not involve school-aged learners, Becker (1996) cited in Ernest (2002), found the model useful when she worked with 31 students of mathematics of both sexes. The model depicts stages of empowerment of the knower, in which students develop as epistemological agents from a position of complete passivity (passive receivers of knowledge) dominated by authority to one of epistemological autonomy and empowerment, as they progress through the stages as shown in Figure 1.

\begin{tabular}{|c|c|}
\hline \multicolumn{2}{|c|}{ Accepting the pronouncements of authority passively } \\
\hline \multicolumn{2}{|c|}{$\begin{array}{l}\text { Received knowledge: The voices of others } \\
\text { Accepting the pronouncements of authority, but able to repeat them }\end{array}$} \\
\hline \multicolumn{2}{|c|}{$\begin{array}{l}\text { Subject knowledge: The inner voice } \\
\text { Responding intuitively, and valuing their own subjective intuitive judgements }\end{array}$} \\
\hline \multicolumn{2}{|c|}{$\begin{array}{c}\text { Procedural knowledge } \\
\text { Seeking objective knowledge by means of either separated or } \\
\text { connected knowing }\end{array}$} \\
\hline $\begin{array}{l}\text { Separated knowing } \\
\text { Impersonal, critical and rational } \\
\text { reasoning, aiming at justification } \\
\text { and proof }\end{array}$ & $\begin{array}{l}\text { Connected knowing } \\
\text { Arising from experience of relationships, } \\
\text { and requiring intimacy and equality } \\
\text { between self and object, knower and } \\
\text { known, aiming at uncritical empathetic } \\
\text { understanding }\end{array}$ \\
\hline $\begin{array}{l}\text { Constructed kn } \\
\text { All knowledge is understood to b } \\
\text { voices of intuition and of reason } \\
\text { depends on the frame of referen } \\
\text { context; the knower is put into r }\end{array}$ & $\begin{array}{l}\text { edge: Integrating the voices } \\
\text { onstructed by the knower herself; and the } \\
\text { integrated into a way of knowing that } \\
\text { f the knower as well as on the overall } \\
\text { ion with the known }\end{array}$ \\
\hline
\end{tabular}

Source: Adapted from Belenky, M.F., Clinchy, B.M., Goldberger, N.R., \& Tarule, J.M. (1986). Women's ways of knowing. New York, NY: Basic Books

FIGURE 1: Model of epistemological empowerment. 
The model depicts shifts in power relations through the stages of epistemological empowerment, from the passive, silent reception of knowledge from authority, through to the active construction of knowledge coupled with the awareness of this power. The strength of this theory is that it accounts for the relative positions, including power relationships that hold between knowledge users and knowledge creators or authorities. The subject is explicitly treated in this theory as the receiver and user of knowledge and we equate this with the learner in our article. The 'other', implicit in this model, is the external source of knowledge and authority and in our case this is the teacher. In the first stage of this theory, silence and received knowledge, the learner or subject has no agency or power and simply receives passively. The transmission metaphor in its most authoritarian form reigns supreme, with the subject being the passive recipient of the absolute knowledge from the 'other'. According to Ernest (2002), the ultimate goal in this model is to achieve the stage of being a 'constructing knower', a learner who can combine intuition and the procedures and skills of mathematics to make sense of the world and confidently apply mathematical thinking.

What this model suggests is that to achieve the epistemological empowerment of learners through mathematics, it is not enough for them to gain mastery over some mathematical knowledge and skills. There needs to be a personal engagement with mathematics so that it becomes an integral part of the learner's personal identity. Based on both a theoretical analysis and on personal experience, Ernest (2002) identified seven different factors that are associated with a shift towards engagement, confidence and epistemological empowerment. However, this article specifically focuses on the following two that we found to be complementary and at the same time consistent with our objectives in this article:

1. A shift in power relations so that the teacher listens to pupils in depth, allows them to make and express judgements and values their contributions.

2. This in turn enables learners to have a sense of 'ownership' of their success - the sense that it results from their own powers and application.

Within this context of shifting power relations, Stinson (2004) cites studies that show how teachers 'teaching from a culturally relevant perspective' could match their teaching styles to the culture and home backgrounds of their learners. In this article we view culture and home backgrounds as embracive terms to refer to all the ways of knowing that the learner brings to the classroom discourse. Of particular relevance to our article is the observation that teachers working from a culturally relevant perspective build from students' ethno or informal mathematics and orients the lesson toward their experiences, whilst developing the students' critical thinking skills. The positive results of teaching from such a perspective are realised when students develop mathematics empowerment. These indicators were valuable in our analyses.

\section{Contextualising the problem of disempowerment}

Within the literature, researchers have shown how it is possible to relate the learning of mathematics to empowerment and democracy (Ernest, 2002; Muller, 2005; Stinson, 2004; Volmink, 1994). This relationship has been examined as a means to underpin a more equitable mathematics education system and to promote a more just society. However, mathematics education can also involve both overt and covert disempowerment, which can occur at all levels of the schooling system. Skovsmose (2000) refers to this as an aporia in that on one hand mathematics education could mean inclusion and empowerment, yet on the other it could also mean suppression, exclusion and disempowerment. It is from this paradoxical observation that some researchers have used the metaphor of mathematics being either a pump or filter: a pump for some by propelling learners into educational opportunities and economic access, and a filter for others by limiting their access to careers and professions. In this context, Volmink (1994) says:

Mathematics is not only an impenetrable mystery to many, but has also, more than any other subject, been cast in the role of an objective judge, in order to decide who in the society 'can' and who 'cannot'. It therefore serves as the gatekeeper to participation in the decision-making processes of society. To deny some access to participation in mathematics is then also to determine, a priori, who will move ahead and who will stay behind. (pp. 51-52)

South Africa presents an ideal site to conceptualise how mathematics education can be overtly as well as covertly disempowering. An important step that was taken postdemocracy was precisely to redevelop education as part of a democratic endeavour. However, a covert form of disempowerment could be seen in the manner in which the national curriculum has been crowned by some 'nice-looking aims and objectives' (Skovsmose, 2004, p. 4) which seem not to translate into practice. For example, pass rates postdemocracy have been on an upward trend, but Jansen (2012) has described this as a 'Matric razzmatazz that conceals a sad reality' as the matriculants who then enter tertiary education institutions find themselves hopelessly out of their depth, whilst those that leave for the job market do not seem to possess the basic numeracy skills they need to be of any use to potential employers. Generally the allegation is that the cognitive demand levels of the examinations have been lowered to the detriment of learners from previously disadvantaged schools (Fleisch, 2008; Muller, 2005). A similar observation is that South Africa was at the bottom of the log in all the Trends in Mathematics and Science Studies (TIMSS) since 1995, giving a false impression that all learners were underperforming. However, further disaggregation of country marks revealed that learners from previously disadvantaged schools performed way below both the national and the international average whilst those from previously advantaged schools performed way above both (Muller, 2005). Such results exemplify covert 
disempowerment of such underperforming learners in terms of access to participation in mathematically related areas.

\section{Methodology \\ Participants}

This article works with archived data collected from four experienced (over seven years) Grade 11 teachers, two men and two women, who took part in a broader study (Mhlolo, 2011). These teachers were all from different previously disadvantaged high schools in South Africa and, through their links with the university, had agreed to take part in the project. Twenty lessons on number, algebra and data handling topics were video recorded and transcribed, generating a 300-page database from which we selected four evaluative events for this article.

\section{Procedure}

\section{Protocol 1 - Evaluative event}

In developing our analytical tool, we borrowed from Adler (2005) who proposed the use of an evaluative event as a possible unit of analysis for what goes on in the mathematics classroom. Adler defined an evaluative event as a teachinglearning sequence that can be recognised as focused on the acquisition or constitution of a particular mathematical object. Andrews (2009) defined it as that part of a lesson where the teacher's didactic intent remained constant. By describing observed pedagogic practices in terms of evaluative event series, it was possible to produce units for the analysis of the pedagogy. In this article we provide four such evaluative events, highlighting the unexpected learner productions. We note immediately a lack of consensus on what might constitute an 'unexpected' learner production in a particular lesson, leading us to the next protocol.

\section{Protocol 2 - Relatability of learner contributions}

We borrowed from Fernandez, Yoshida and Stigler's (1992) proposition of relatability of events, which builds on the presumption that not all relations between events must be presented for learning to occur because some events are not relevant to the content of the lesson. Fernandez et al. suggest that following the teachers' objectives (explicit or implied) for the lessons, and their responses to learner productions, one can judge whether or not learner productions were:

1. Relatable and relevant, hence expected and critical for learning to take place.

2. Not relatable, hence unexpected and irrelevant for understanding the mathematical ideas.

3. Relatable but, depending on the teachers objective, not immediately expected or relevant for critical understanding.

In the absence of teachers' explicit or implied objectives, Fernandez et al. (1992) suggest that those characteristics of a lesson that make it easier to represent mathematical ideas coherently are closely related. These ultimately facilitate effective teaching and learning of content; hence, they are likely to enable learners to be authors and producers of mathematical knowledge. Teachers' responses to such learner productions are influenced by their listening orientations; hence, we were also interested in the extent to which such orientations were conducive to a democratic and empowering mathematics classroom.

\section{Protocol 3 - Listening orientations}

A listening orientation can contribute to mathematical empowerment in the sense that it is linked to a fundamental principle underlying the constructivist approach to learning mathematics: that one of the teacher's responsibilities is to listen and determine or interpret the learners' rationality and meaning (Cobb \& Yackel, 1998). An important part of teaching mathematics is to support learners to voice their mathematical thinking and reasoning, nascent or flawed as it might be (Brodie, 2010). When teachers do not listen to or do not understand their learners' thinking, they are likely to be ineffective; hence, Ball and Forzani (2010) posit that:

Teaching without attention to learners' perspectives and prior knowledge is like flying a plane in fog without instruments. This has big implications for equitable education because the greater the differences between learners and their teachers - in culture, language, and experience - the less precisely attuned the teaching is likely to be. (p. 41)

In terms of promoting democratic values, when teachers do not listen to or do not understand their learners' thinking they tend to dismiss such thinking by imposing their own formalised constructions onto the learners (Cobb \& Yackel, 1998; Davis, 1997), thereby instilling non-democratic values. According to the Belenky et al. (1986) model this would be the stage dominated by authority and therefore less selfempowering for the learner.

Although there are various ways in which teachers can listen to their learners' mathematical ideas, Davis (1997) posits that not all listening orientations are conducive to and respectful of learners' thinking. He discussed three different orientations teachers might have towards listening in the mathematics classroom: 'evaluative', 'interpretive' and 'hermeneutic'. Teachers with an evaluative orientation, according to Davis, tend to listen to learners' ideas in order to diagnose and correct their mathematical misunderstandings. With an evaluative listening orientation, the learners' work is seen in light of how the teacher would approach the problem as well as their expectations for how the problem might be solved.

Teachers with an interpretive orientation, on the other hand, listen for something rather than listening to learners' ideas. Listening for something suggests that the teacher is not interested in what the learner is saying. According to Brodie (2010), such teachers often ask questions that address particular aspects or points that they are looking for. When a learner produces an unexpected contribution, they usually do not entertain that response, but continue to look for a response that would be consistent with their thoughts. 
Teachers with a hermeneutic orientation, on the other hand, interact with their learners, listening to their ideas and engaging with them in the messy process of negotiation of meaning and understanding. Sherin (2002) referred to it as adaptation: teachers listen, interpret and respond to their learners' mathematical ideas by modifying and building on both the learners' and teacher's existing subject matter knowledge and pedagogical content knowledge. Thus, it is the hermeneutic orientation for teaching that is particularly needed if teachers are to take an adaptive or negotiating approach to the implementation of reform-based tasks (Doerr \& English, 2006). Therefore, for us a hermeneutic listening orientation is at the heart of an empowering and democratic classroom. Putting these three protocols together, our unit of analysis was an evaluative event. In it, we were interested in identifying the unexpected learner productions, and the manner in which the teacher listened to and dealt with such novel comments or actions.

\section{Validity and reliability}

Our measures for obtaining internal reliability included systematic selection of learner contributions from video clips, using a relatability tool to justify that such contributions were unexpected by the teacher. We then used a protocol to capture the teacher's responses to such contributions to justify whether there was evaluative listening or hermeneutic listening on the part of the teacher. The protocol and analyses were shared with colleagues (peer examination) at conferences and local workshops. In order to enhance quality of our justification and conclusions, we submitted articles and conference contributions that were reviewed during the research period.

\section{Ethical considerations}

Approval to proceed with this study was granted by the Department of Education. At institutional level, approval was granted by the university ethics committee. At school level the first author obtained informed consent from the principals, teachers and parents of the learners who were to be involved in this study. At both school and individual levels the participants' anonymity and confidentiality were maintained through the use of pseudonyms (e.g. Teacher $\mathrm{M}$, Learner 2) and the fact that the video recording was not focused on either the teacher or the learner.

\section{Analysis of results}

Whilst there are many learner contributions that we could have exemplified, we only present the four evaluative events (one from each teacher) that we chose for this article. The criterion for selecting these four was that, in our view, these were at the core of the mathematical object that was being focused on in each of the series of lessons and were therefore critical for learners to have a conceptual understanding of that particular object. The analyses we make thereof particularly focus on whether or not the teacher listened with the intention to reject or accept (evaluative), or to adopt and adapt (hermeneutic).

\section{Evaluative event 1 - Multiplication of polynomials}

In this event, the teacher was dealing with the multiplication of polynomials applying the distributive law. The examples that had been worked with so far were of the form $(a+b)(c+d+e)$. The teacher wrote five tasks on the board; task E was $\left(3 x^{2}+x y-2 y^{2}\right)(x+2 y)$. The learner who had been tasked to do this problem, worked on the board thus:

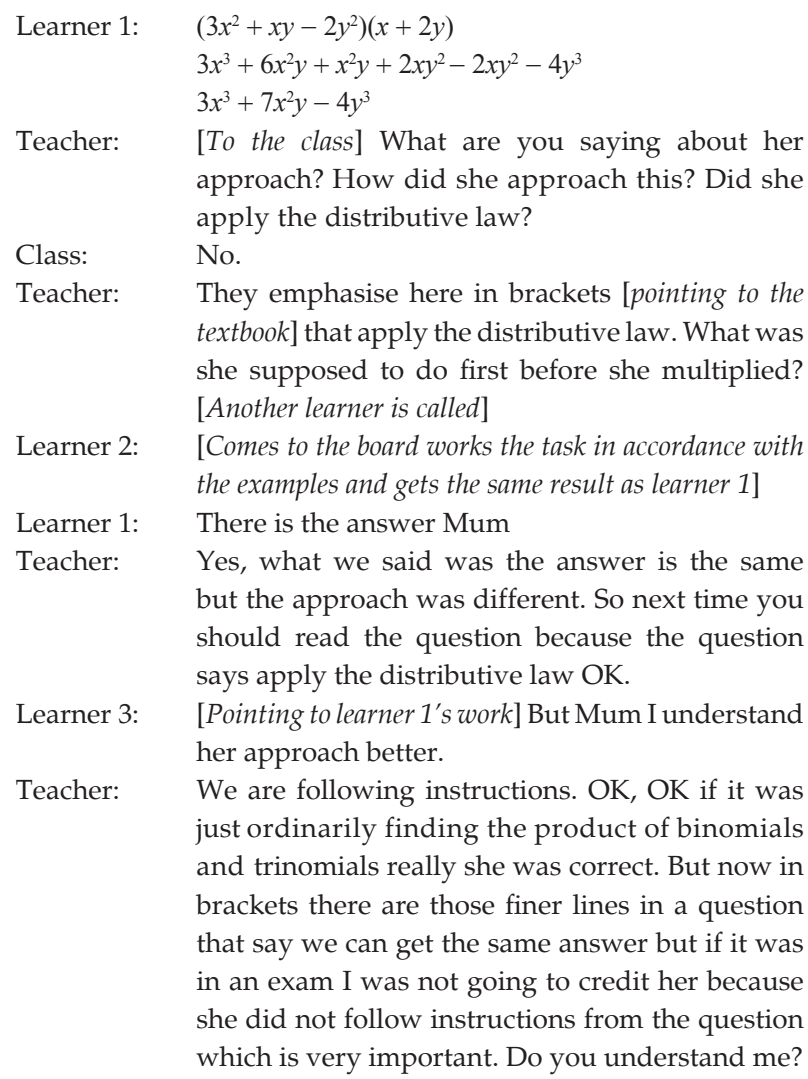

\section{Comment}

In our view the teacher's comment, 'They emphasise here in brackets ...' showed that the teacher had a different expected image of the distributive law and Learner 1's contribution was unexpected. Through the commutative law where $a \times b$ is equivalent to $a \times b$, we argue that the learner's contribution was relatable as we see it as a mathematically reasoned equivalent. Nevertheless, because the learner did not rearrange the polynomials to start with the binomial on the left, the teacher raised the question for the class: 'Did she apply the distributive law', leading to the contribution being rejected.

\section{Evaluative event 2 - General term of a linear sequence}

In this lesson, the teacher introduced the general term of a linear sequence:

Teacher: $\quad$ [Writes $] 4 ; 7 ; 10 ; 13 ; \ldots$

Alright, I want us to observe a pattern here. Term number 1 is 4 . What has been done to this 1 to make 4; the same thing should be done to this 2 to make 7 ; the same thing should be done to this 3 to make $10 ; \ldots$ 


\section{Class: $\quad$ Multiply by 3 and add 1}

Teacher: $\quad$ So what shall the general term be?

Class: $\quad \mathrm{T}_{n}=3 n+1$

Teacher: $\quad$ [Writes] $3 ; 7 ; 11 ; 15 ; \ldots$

Alright you are given these first four terms of the sequence; the general term? Ooo I'm seeing the same hands. Why the same hands? Eeeee, [name of learner].

Learner 1: $\quad \mathrm{T}_{n}=4 n-1$

Learner 2: Can I please ask a question. You see I just want to find out why isn't that to find the $\mathrm{T}_{n}=\mathrm{bla}$, bla, bla? [referring to $T_{n}=4 n-1$ ]. Why can't you just add tose numbers I mean for example like three $\left[T_{l}\right]$ then you add one, two, three, then you get four [constant difference] then you put the four instead of getting all the other things for the $\mathrm{T}_{n}$.

Teacher: OK you can start afresh. What are you saying, what are you suggesting?

Learner 2: Sir why can't we just like find the differences?

Teacher: We find the differences fine, like in this case the difference is what, it's four.

Learner 2: Yaah it is four.

\section{Teacher: It is four.}

Learner 2: Yaah. Then why is it that you can't write like $\mathrm{T}_{n}=$ bla bla +4 ? Why do you have to write -1 that's my question?

Teacher: Right, the general term is some kind of a formula that will be used to generate all the terms of the sequence. It's OK.

Learner 1: Yes, yes.

Teacher: Right. Can you say $\mathrm{T}_{n}=4$ is a formula?

Class: Noooo.

Teacher: [To Learner 2] OK, alright I thought you had made an observation.

Learner 2: Sir I do have an observation!

Teacher: $\quad$ OK order, alright OK, let's give somebody else a chance. [The learner is then ignored and the lesson continues]

\section{Comment}

The teacher's direct link between the $\mathrm{T}_{n}$ and the values suggests the explicit rule as the object. However, in this rule the 3 and 4 which are constant differences in the first and second sequences respectively are masked, yet this is how the learner understood the number sequence. Judging by the teacher's response ('I thought you had made an observation', then ignoring the learner), Learner 2's talk was 'unexpected' but relatable as it suggests a recursive formula as an entry point. Again we notice that the learner has no agency or power and simply receives the teacher's version passively.

\section{Evaluative event 3 - Graphical display of data}

In this event, data had been collected in a survey about families. The top row in Table 1 shows the number of children in each family whilst the bottom row shows the corresponding number of families.

The teacher began by asking the class how the data in the table could be displayed, and received 'bar graph' as one of the responses. A pupil was then asked to draw the first bar. The learner started by drawing $x$ and $y$ axes intersecting at 0 as shown in Figure 2.
The learner then drew a vertical bar, approximately a quarter of a unit wide and eight units high:
Teacher: Is he correct?
Class: $\quad$ Somehow, almost, maybe.
Learner: That bar shows a quarter and eight ma'am.
Teacher: $\quad$ OK so the zero was supposed to be where? Here?

The teacher then added another zero on the $x$-axis (what she was expecting) such that the pupil's bar now sat between two zeros. She then asked whether the learner would have been correct if the zero was in this second position. Although one pupil said, 'Maybe it's incorrect', the teacher ignored this, perhaps because the zero was now where she wanted it to be. She asked another pupil to add in the next bar for 14 and 1. This second bar was drawn across to the 'one' on the $x$-axis. Another pupil drew the third bar for 20 and 2 going across to the ' 2 ' on the $x$-axis and 20 high.

On seeing that some learners were declaring the graph incorrect:

Teacher: OK fine, all right fine, our example OK, I chose it because I wanted you to see something. If you have zero, as a number included, don't, this is the point of origin by the way [pointing to the intersection of the axes]. OK so don't make zero your point of origin. So think this as a Cartesian plane whereby the number before zero will be what, a negative one.

\section{Comment}

Judging by both the objective of the event (drawing a bar graph for categorical data) and the teacher's responses, we argue that a two-dimensional chart with axes intersecting at 0 was 'unexpected' but relatable given the links that exist between such surfaces on which graphs are drawn. A graph is a representation of numerical values or functions by position

TABLE 1: Number of children in each family and their frequencies.

\begin{tabular}{|l|c|c|c|c|c|c|}
\hline No. of children in each family & 0 & 1 & 2 & 3 & 4 & 5 \\
\hline No. of families (Frequency) & 8 & 14 & 22 & 7 & 0 & 1 \\
\hline
\end{tabular}

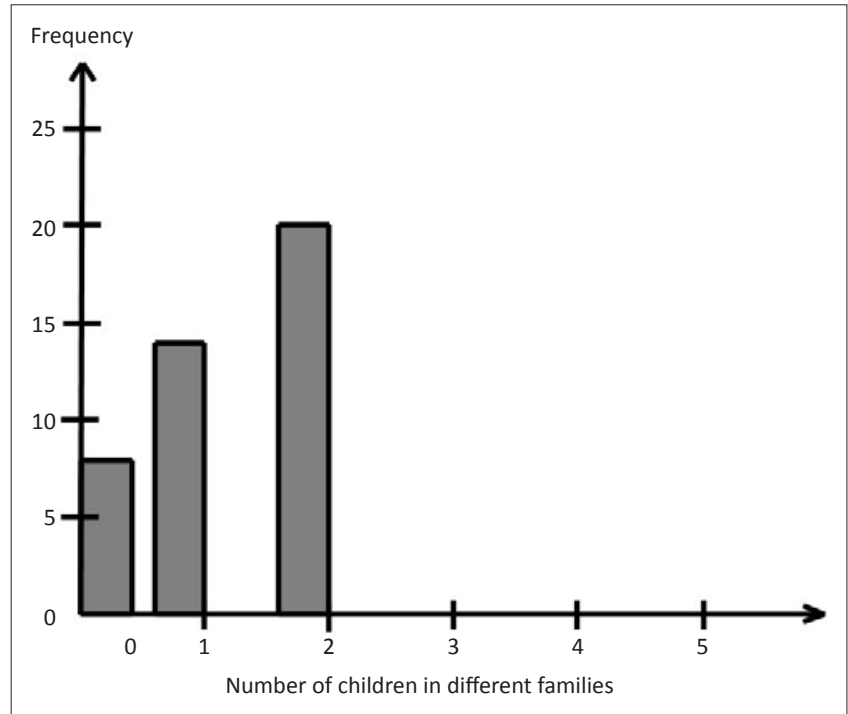

FIGURE 2: Learner's drawing of bar graph of survey data. 
of point, line or area on a two-dimensional surface or chart. Each chart area contains an $x$-axis (horizontal) and a $y$-axis (vertical) which are the objects for its plot area. These axes can be named differently to correspond with the variables of interest. Friel, Curcio and Bright (2001) warn that interpreting graphs that utilise two axes may present difficulties if the functions of the axes across these graphs are not explicitly recognised. It would appear that this error, in recognition of the functions of the two axes across graphs, is at the centre of confusion in this event.

\section{Evaluative event 4 - Factorisation of trinomials}

The teacher wrote the following trinomial on the board: $a^{2}+14 a+48$. The lesson was on factorisation and the method involved finding factors of the last term (48) which would add to the middle term (14), hence:

$$
a^{2}+14 a+48=(a+6)(a+8)
$$

A few more examples were worked out including the following one with a negative middle term:

$$
n^{2}-16 m n+15 m^{2}=(n-m)(n-15 m)
$$

Teacher: Any question so far?

Learner 1: What if there is a division?

Teacher: Division where? Come and write it on the board.

Learner 1: [Writes on the board] $n^{2}-\frac{16}{m n}+15 m^{2}$

Class: Aaaaaaa!

Teacher: Listen, is it possible that you find an expression like that?

Class: Nooooo

Teacher: Let us proceed then. Any other questions?

\section{Comment}

From the teacher's response, we argue that the learner's contribution was unexpected. The relatability of the learner's contribution, however, could be seen in terms of providing a counter-example, without which learners were likely to conjecture that all trinomials can be factorised this way. Our view is that such factorisation is a critical tool when solving quadratic equations.

\section{Discussion}

We first examined the extent to which teachers gave authority to their learners' novel comments and actions. In the first set of lessons, focusing on the multiplication of polynomials, a learner used her own personal method to deal with the expansion of brackets, which the class was also comfortable with. However, because she was not familiar with it, the teacher did not acknowledge it as an equivalent. The result is that, for the whole week, tasks on multiplication of polynomials were solved in the teacher's way: binomial to the left, trinomial to the right. In the Belenky et al. (1986) model, this depicts power relations at the first two levels: learners accept the pronouncements of the teacher's authority passively and are able to repeat them. Ernest (2002) sees this as epistemological disempowerment as it deprives the learners of their personal creation and validation of knowledge.
In the second set of lessons that we analysed, the focus was on deriving formulae for linear number sequences. The teacher's entry point was an explicit rule whilst one learner argued vehemently for a recursive rule. She was called to order by the teacher and the lesson continued in the teacher's way. In this sense, we also see the transmission metaphor reigning supreme with the learners being passive recipients of the absolute knowledge from the teacher (Ernest, 2002). With specific reference to the generation of a recursive or explicit rule for a sequence, Blanton (2008) cautions that it is important to listen to how learners' verbal statements imply that they are looking at the ways that quantities change (recursive), or that they are making a prediction based on the connection between the term number and its value (an explicit general term). Recursive reasoning is seen as a building block for the eventual ability to use formulae that directly determine any unknown amount. Such reasoning emerges naturally, as learners develop skip counting and the ability to add on. For learners in the early stages, instruction that encourages them to look for recursive patterns in functional situations is a recommended starting point for developing algebraic thinking (Bezuszka \& Kenney, 2008).

Our view is that deriving these formulae through the recursive would have empowered the learners as they would have made sense of the relationships between the more familiar (recursive rule) and what was new to them (explicit rule). We argue that the teacher's extraction of the general terms $3 n+1$ and $4 n-1$ in both cases was rote, limited and therefore disempowering both in terms of masking the idea of 3 or 4 being constantly added and in terms of its generalisability to other cases, such as $27,30,33,36, \ldots$

In the series of lessons focusing on drawing bar charts, we saw more of what Brodie (2010) refers to as an interpretive orientation: the teacher did not build on the learner's idea of a two-dimensional plane with axes intersecting at 0 . The teacher's shifting of zero to the position at which she was expecting it to be shows she was not listening with the intention to understand the learner's mathematical reasoning. She was drawing the learner's contribution close to her own established disposition. Her directions thereof reflect a more procedural orientation than conceptual in that the learners were simply told that if zero is a number in their data set, then they should not put a zero at the origin. To us this was an indication of the teacher imposing her own formalised constructions onto the learners without saying why this is problematic. Consequently, the teacher's shifting of the zero to a new position does not resolve the issue of recognising the scaling of the $x$-axis in this context. The overall mathematical outcome here is a bar graph that does not represent the original data set particularly well, either in terms of mathematical structure and convention, or with reference to the real-world situation being represented, which is thus less empowering for the learners.

In the last vignette focusing on factorisation of trinomials, we note the teacher soliciting questions from the learners: 'Any question so far?' One learner raises a question that in 
our view would have provided a special case or counterexample to the type of tasks that were being dealt with. The teacher however did not attend (listen) to the mathematics within what the learner was saying and neither did he assess the mathematical validity of the learner's ideas, and try to make sense of the learners' mathematical thinking (Ball \& Forzani, 2010). Instead of determining the learner's rationality (Cobb \& Yackel, 1998) and teaching from the learner's perspective (Ball \& Forzani, 2010), he dismissed it with ridicule, presumably because it was not in line with his own formalised construction (Davis, 1997). The literature alludes to such practices, such as Gruenwald and Klymchuk (2003) who noted that sometimes mathematics courses, especially at school level, are taught in such a way that special cases are avoided and learners are exposed only to 'nice' functions and 'good' examples. This approach can create many misconceptions, as explained in Tall's (1991) generic extension principle:

If an individual works in a restricted context in which all the examples considered have a certain property, then, in the absence of counter-examples, the mind assumes the known properties to be implicit in other contexts. (p. 18)

There are many areas of mathematics where opportunities abound for learners to investigate whether a conjecture is always, sometimes or never true (Gruenwald \& Klymchuk, 2003). We note quickly that the quadratic formula and other algorithms were born out of a realisation that some quadratic expressions cannot be factorised using the algorithm that was used throughout the series of lessons. Here was an opportunity for the teacher to negotiate and adapt the learner's counter-example for other learners to conclude by themselves that sometimes a trinomial could not be factorised in this way. We therefore argue that the teacher's action did not foster and facilitate learners to take power over the creation and validation of their mathematical knowledge (Ernest, 2002).

\section{Practical implications}

Data analysed in this article suggest that the everyday practice of inviting students to contribute responses to a mathematical question or problem may do little more than promote cooperation. In order to be consistent with a democratic and empowering classroom, teachers who truly care about the development of their students' mathematical proficiency need to show genuine interest in the ideas learners construct and express, no matter how unexpected or unorthodox. One way of achieving this is to take note of the learners' contributions that might not have been resolved in class, consult peers and use such contributions as launching pads for further learning.

\section{Limitations}

We note and acknowledge one reviewer's observation that our vignettes do not seem to exemplify hermeneutic listening. Perhaps this gap could best be explained in terms of the prevalence of 'expected' and 'unexpected' learner contributions. Common classroom practice is that teachers go into class expecting certain questions to be raised by learners and for an experienced teacher such expected questions far outnumber the unexpected. The tendency is that learners' questions are then shaped to be consistent with aspects that teachers are looking for - an interpretive orientation. It is for this reason that, in the context of our concept of a democratic classroom, we were specifically interested in identifying the 'unexpected' learner productions and the manner in which the teacher dealt with them. Admittedly these are few, hence the reviewer's concern, but the literature (Brodie, 2010) confirms our findings that when learners produce unexpected contributions, teachers usually do not entertain such responses even though this is critical for learner empowerment in a democratic classroom.

\section{Conclusion}

All the learners' contributions that we analysed had the potential to be exploited to enhance learners' understanding of the related mathematical ideas. However, whenever they occurred in the lessons the teachers either explicitly or tactfully ignored them. Such teacher behaviour is not consistent with giving epistemological empowerment to learners and suggests that the teachers are less democratic in their orientation.

\section{Acknowledgement}

We acknowledge the Department for International Development for funding the $\mathrm{PhD}$ study from which this article draws. The views expressed in this article are not necessarily those of the funders.

\section{Competing interests}

The authors declare that we have no financial or personal relationship(s) which might have inappropriately influenced our writing of this article.

\section{Authors' contributions}

M.K.M. (Rhodes University) conducted all the research and wrote the manuscript. M.S. (Rhodes University) made major conceptual contributions to this article.

\section{References}

Adler, J. (2005). Mathematics for teaching: What is it and why is it important that we talk about it? Pythagoras, 62, 2-11. http://dx.doi.org/10.4102/pythagoras.v0i62.109

Andrews, P. (2009). Comparative studies of mathematics teachers' observable learning objectives: Validating low inference codes. Educational Studies in Mathematics, 71(2), 97-122. http://dx.doi.org/10.1007/s10649-008-9165-x

Ball, D.L., \& Forzani, F.M. (2010). Teaching skilful teaching. Educational Leadership, 68(4), 40-45.

Belenky, M.F., Clinchy, B.M., Goldberger, N.R., \& Tarule, J.M. (1986). Women's ways of knowing. New York, NY: Basic Books.

Bezuszka, S.J., \& Kenney, M.J. (2008). The three R's: Recursive thinking, recursion, and recursive formulas. In C.E. Greenes, \& R.N. Rhubenstein (Eds.), Algebra and algebraic thinking in school mathematics. 17th yearbook of the National Council of Teachers of Mathematics (pp. 81-97). Reston, VA: NCTM.

Blanton, M. (2008). Algebra and the elementary classroom: Transforming thinking, transforming practice. Portsmouth, $\mathrm{NH}$ : Heinemann.

Boaler, J. (1993). The role of contexts in the mathematics classroom: Do they make mathematics more real? For the Learning of Mathematics, 13(2), 12-17. Available from http://www.jstor.org/stable/40248079 
Brodie, K. (2010). Teaching mathematical reasoning in secondary school classrooms. New York, NY: Springer. http://dx.doi.org/10.1007/978-0-387-09742-8

Cobb, P., \& Yackel, E. (1998). A constructivist perspective on the culture of the mathematics classroom. In F. Seeger, J. Voigt, \& U. Waschescio (Eds.), The culture of the mathematics classroom: Analysis and changes (pp. 158-190). New York, NY: Cambridge University Press. http://dx.doi.org/10.1017/CBO9780511720406.007 PMid:9688530

Davis, B. (1997). Listening for differences: An evolving conception of mathematics teaching. Journal for Research in Mathematics Education, 28(3), 355-376. http:// dx.doi.org/10.2307/749785

Doerr, H.M., \& English, L.D. (2006). Middle grade teachers' learning through learners' engagement with modelling tasks. Journal of Mathematics Teacher Education, 9(1), 5-32. http://dx.doi.org/10.1007/s10857-006-9004-x

Ernest, P. (2002). Empowerment in mathematics education. Philosophy of Mathematics Education Journal, 15, 3-13. Available from http://people.exeter.ac.uk/PErnest/ pome15/ernest_empowerment.pdf

Fernandez, C., Yoshida, M., \& Stigler, J.W. (1992). Learning mathematics from classroom instruction: On relating lessons to learners' interpretations. Journal of the Learning Sciences, 2(4), 333-365. http://dx.doi.org/10.1207/s15327809jls0204 1

Fleisch, B. (2008). Primary education in crisis: Why South African school children underachieve in reading and mathematics. Cape Town: Juta.

Friel, S.N., Curcio, F.R., \& Bright, G.W. (2001). Making sense of graphs: Critical factors influencing comprehension and instructional implications. Journal for Research in Mathematics Education, 32(2), 124-158. http://dx.doi.org/10.2307/749671

Gruenwald, N., \& Klymchuk, S. (2003). Using counter-examples in teaching calculus: Learners' attitudes. The New Zealand Mathematics Magazine, 40(2), 33-41.

Jansen, J. (2012, January 07). Matric razzmatazz conceals sad reality. Saturday Argus. Available from http://www.iol.co.za/news/south-africa/western-cape/matricrazmatazz-conceals-sad-reality-1.1209349\#.ULOERYaDoq
Lather, P. (1991). Getting smart: Feminist research and pedagogy within the postmodern. New York, NY: Routledge.

Mhlolo, M.K. (2011). From coherence in theory to coherence in practice: A stock-take of the written, tested and taught National Curriculum Statement for Mathematics (NCSM) at further education and training (FET) level in South Africa. Unpublished doctoral dissertation. University of the Witwatersrand, Johannesburg, South Africa. Available from http://wiredspace.wits.ac.za//handle/10539/11274

Muller, J. (2005, June). The challenge of cognitive demand. Paper presented at the Umalusi Seminar on "Matric: What is to be done?", UNISA Senate Hall, Pretoria. Available from http://umalusi.org.za/ur/research/muller.pdf

Sayed, Y., \& Jansen, J. (Eds.) (2001). Implementing education policies: The South African experience. Cape Town: University of Cape Town Press.

Sherin, M.G. (2002). When teaching becomes learning. Cognition and Instruction 20(2), 119-150. http://dx.doi.org/10.1207/S1532690XCl2002_1

Skovsmose, O. (2000). Aporism and critical mathematics education. For the Learning of Mathematics, 20(1), 2-8. Available from http://www.jstor.org/stable/40248312

Skovsmose, O. (2004, July). Critical mathematics for the future. Paper presented at the 10th International Conference on Mathematical Education, Copenhagen, Denmark.

Stinson, D.W. (2004). Mathematics as "gate-keeper"?: Three theoretical perspectives that aim toward empowering all children with a key to the gate. The Mathematics Educator, 14(1), 8-18. Available from http://math.coe.uga.edu/tme/Issues/v14n1/ v14n1.Stinson.pdf

Tall, D. (1991). The psychology of advanced mathematical thinking. In D. Tall (Ed.), Advanced mathematical thinking (pp. 3-21). Dordrecht: Kluwer Academic Publishers. http://dx.doi.org/10.1007/0-306-47203-1

Volmink, J. (1994). Mathematics by all. In S. Lerman (Ed.), Cultural perspectives on the mathematics classroom (pp. 51-67). Dordrecht: Kluwer Academic Publishers. 